Необычность, деловая активность, эмоциональное восприятие информации, ограниченность во времени на выполнение задания и принятие решений - все это мобилизует и дисциплинирует каждого курсанта в процессе обучения.

Экспериментальное обучение с применением специально разработанных методик и комплексных штурманских деловых игр по специальным дисциплинам позволит более эффективно сформировать личность специалиста, привить ему навыки профессионального общения, проявить творческую инициативу в решении профессиональных задач, а также сделать еще один шаг вперед на пути формирования профессиональной компетентности будущего специалиста-штурмана.

Целью наших дальнейших исследований является разработка новых критериальнопоказательных методов оценки уровней сформированности профессиональной компетентности курсантов-штурманов.

$$
* * *
$$

1. Агапов, И.В., Алешин, С.В. Воробьев, О.А. и др. Формирование и развитие профессионально важных качеств у курсантов в процессе обучения в ВВАУЛ [Текст]: методическое пособие/ И.В. Агапов, С.В. Алешин, О.В. Воробьев. - М.: Воениздат, 1992. - 184c.

2. Белкин, А.С. Компетентность. Профессионализм. Мастерство [Текст]: учебное пособие / А.С. Белкин Челябинск: ОАО «Южно-Уральское кн. изд-во», 2004. - 176с.

3. Зеер, Э.Ф. Личностно ориентированное профессиональное образование [Текст]: учебное пособие / Э.Ф. Зеер - Екатеринбург: Урал. гос. проф.-пед. ун-т, 1998. - 51с.

4. Зеер, Э.Ф. Модернизация профессионального образования: компетентностный подход [Текст]: Статья / Э.Ф. Зеер - Образование и наука. - 2004. - № 3.

5. Львов, Л.В. Психология и педагогика профессиональной деятельности [Текст]: учебное пособие / Л.В. Львов - Челябинск: ЧГАУ, 2005. - 144c.

6. Львов, Л.В. Практическая подготовка штурмана [Текст]: методическое пособие / Л.В. Львов - Челябинск: ЧВВАУШ, 2000. - 48c.

\title{
Воронежская А.М. \\ Современные технологии экологического воспитания старших школьников с элементами медиаобразования
}

Таганрогский институт имени А.П. Чехова (филиал) «Ростовского государственного экономического университета (РИНХ)» (Россия, Таганрог)

doi: 10.18411/trnio-11-2021-145

\section{Аннотация}

В статье рассматриваются теоретические проблемы экологического воспитания современной молодежи с использованием медиаобразовательных компонентов. Автором представлен анализ современных технологий экологического воспитания на материале произведений медиакультуры, представлен процесс интеграции экологического воспитания на материале медиакультуры в учебно воспитательный процесс.

Ключевые слова: медиа, медиакультура, медиаобразование, экологическое воспитание, молодое поколение.

\section{Abstract}

The article deals with the theoretical problems of ecological education of modern youth using media educational components. The author presents an analysis of modern technologies of environmental education on the material of works of media culture, presents the process of integrating environmental education on the material of media culture into the educational process. generation.

Keywords: media, media culture, media education, environmental education, young 
Нынешнее молодое поколение существует в ситуации обострения глобальных экологических проблем, имеющих абсолютно определенное представление о негативной экологической ситуации в множества регионах Российской Федерации. Близкая связь человека с миром природы, взаимозависимость, что появляется в взаимосвязи с вмешательством людей в природу, приводят к потребности сбережения слабого экологического баланса на нашей земле.

Нельзя не согласится с тем, что все без исключения области жизнедеятельности современного молодого поколения неразрывно связаны с областью медиа. Во взаимосвязи с данной областью, в ходе экологического обучения, все без исключения стремительно применяют разнообразные работы медиакультуры (кинофильмы, телевизионные проекты, использованные материалы в периодические прессы).

Ход интеграции медиаобразования в процедуре экологического обучения способствует решению некоторых значимых вопросов.

1. Подготовка восприятия также переработке данных экологической темы, представляемой по каналам средств массовой коммуникации.

2. Формирование умений понимать тайный смысл уведомлений в экологическую проблему, противодействовать манипулированию сознанием индивидуума со стороны СМК.

3. Введение внешкольной информации по экологии, с единым базисным образования, в концепцию формируемых в настоящих сферах познаний и умений.

4. Развитие умений обнаруживать, транслировать, осуществлять и формировать медиапроизведения экологической темы с использованием материала компьютерной технологии, телевидения, видеоматериал и т. д. [1].

Во многих школах проводятся внеурочные занятия по экологическому воспитанию обучающихся старших классов, но работы медиакультуры захватывают в подобных упражнениях весьма небольшую роль также больше в целом применяются в свойстве явных учебных пособий.

Ведущими идеями современных экранных произведений на экологическую тему являются следующие:

- серьезные нарушения экологического баланса фактически уже не обратимы;

- самые страшные экологические деформации затрагивают человеческое сознание» [2].

Почти все без исключения разновидности медиакультуры (телевещание, киноискусство, видеоматериал, печать, Сеть Интернет) затрагивают экологическую проблему.

Телевещание не прекращает пользоваться довольно огромной известностью в молодежной сфере и обдает наиболее различными сведениями: просветительной, увеселительной, познавательной. Природная тема кроме того показана в творениях телевидения медиакультуры.

Например, на российском телеэкране представлены целые циклы программ и фильмов на тему взаимодействия человека и природного мира. К таким программам относятся:

- популярные и научно-популярные фильмы о природе («Подводный мир», «Медвежонок», «Мир дикой природы» и др.);

- разнообразные авторские телевизионные передачи («Среда», «Записки натуралиста», «В мире животных» и др.);

- художественные фильмы, транслируемые по ТВ на экологическую тему («Сталкер», «Письма мертвого человека» и т.д.) [1].

Данная деятельность урочного обучения на тему экологического образования применяется во многих школах в виде видеозаписей. 
О.А. Барановым и С.Н. Пензиным выдвигаются определенные требования к организации занятий по экологическому образованию и воспитанию:

- удобный для работы на занятии формат передачи (10-15 минут);

- наглядность представленных материалов и доступность звукового ряда;

- coответствие темы передачи и содержания образовательного стандарта;

- расчет на диалоговое восприятие и активизацию зрителя;

- наличие подробных методических материалов к данным передачам [1].

На наш взгляд термин «медиаобразование» больше применим копределению педагогического процесса, тогда как термин «медиа-грамотность» определяет сформированное (или не сформированное) качество личности человека. Но, по-нашему мнению, медиаграмотность - это лишь первоначальный, самый примитивный результат процесса медиаобразования.

Проблемой интегрированного медиаобразования в настоящее время занимаются такие исследователи как И.В. Челышева и Г.В. Михалева, Т.М. Чурекова, М.А. Щербакова и др.

К примеру, И.В.Челышева и Г.В.Михалева отмечают, что «в российской медиапедагогике интегрированный подход был тесно связан с положениями эстетической, культурологической и этической концепций. Интеграция элементов медиаобразования в учебно-воспитательный процесс связывалась, прежде всего, с учебными предметами художественного цикла, факультативами и кружками, где углубленно изучались литература, мировая художественная культура, изобразительное искусство, музыка и т.П., и основывалась на позициях приобщения подрастающего поколения к миру культуры» [4].

T.М. Чурекова, М.А. Щербакова считают, что использование интегрированных форм медиаобразования «приводит к необходимости использования на уроке не только готовых или созданных преподавателем медиаресурсов, но и медиаисточников, разработанных учащимися совместно с учителем во время внеклассной работы» [5].

При этом во взаимосвязи с потребностью соблюдения в целом комплекса назначенных педагогических условий, работа обучающихся также преподавателя должна реализоваться в то же время согласно двум тенденциям.

Первая тенденция, связанная с применением упражнений в рамках учебных дисциплин с использованием различных медиаресурсов, представляет собой по сути закономерное продолжение информационно-теоретической подготовки старшеклассников. Эта работа не только обеспечивает последовательность в осуществлении частей содержательного блока экологического воспитания, но также способствует развития креативных возможностей.

В рамках второй тенденции, старшеклассники в процессе внеклассной деятельности включаются в общую с преподавателем созидательную работу по формированию экологической воспитанности с использованием медиатекстов и медиаресурсов разной трудности. В этом случае хорошо показало себя использование парной и коллективный форм работы. Эта работа позволяет старшеклассникам развивать поисковые умения, совершенствовать навыки подбора медиаисточников и носителей информации» [3].

Практически все виды медиакультуры (телевидение, кинематограф, видео, пресса, интернет) различных видов и жанров затрагивают экологическую тему. «Большую роль в раскрытии экологической темы всегда играло киноискусство» [1].

Технология экологической деятельности с молодыми людьми с использованном материала экранной медиакультуры подразумевает решение креативных медиаобразовательных задач. Кинофильмы экологической тематики имеют все шансы использоваться в преподавательской работе с целью расширения горизонта учащихся по проблемам экологического воспитания.

Таким образом, особенность экологического воспитания нынешнего юного поколения требует непрерывного поиска новейших способов с целью привлечения интереса к глобальным проблемам экологии. Высококачественные кинокартины экологической 
проблематики дают возможность четко показать предпосылки появления, результаты природоохранных, а также общественных вопросов, связанных с экологическим воспитанием.

1. Баранов О. А., Пензин С. Н. Медиа, современная семья и школьник // Медиаобразование. 2006. №2. URL: https://cyberleninka.ru/article/n/media-sovremennaya-semya-i-shkolnik.

2. Бурлакова Т.Ю. Педагогические условия организации образовательной деятельности по экологическому воспитанию дошкольников: дис. канд. пед. наук. М., 2016. 168 с.

3. Колыванова Л. А., Носова Т. М. Инклюзивное биоэкологическое образование в аспекте модернизации профессиональной подготовки студентов колледжа. В сборнике: Модернизация естественнонаучного образования: методика преподавания и практическое применение сборник статей IV Международной научно-практической конференции, посвященной 85-летию естественно-географического факультета ФГБОУ ВПО ПГСГА. 2014. С. 98-104.

4. Моисеева Л. В. Альтернативные модели экологического образования / Л. В. Моисеева. — Екатеринбург: УрГПУ, 2004. - $156 \mathrm{c}$.

5. Модели создания воспитывающей среды в образовательных организациях, организациях отдыха детей и их оздоровления: наука, технологии, практики / под ред. Т.Н. Владимировой ; Министерство науки и высшего образования Российской Федерации, 2018. - 454 с.

\section{Гаглоева Э.Н., Намшуридзе Г.Г. Инженерная педагогика как система подготовки преподавателей технического направления}

Юго-Осетинский государственный университет им.А.А.Тибилова (Южная Осетия, Цхинвал)

doi: 10.18411/trnio-11-2021-146

\section{Аннотация}

В статье говорится об инновационных подходах к подготовке преподавателей технического направления. Также говорится о важности гуманистической направленности в техническом образовании в целом. Приводятся обоснования особой роли метапредметности, трансдисциплинарности в ходе подготовки специалистов для обучения техническим наукам. Рассматриваются условия и возможности подготовки профессионально ориентированных специалистов в сфере образования, готовых модернизировать современный образовательный процесс.

Ключевые слова: инженерная деятельность, профессиональная педагогика, профессиональные компетенци, техническая педагогика, образовательные профессиональные стандарты, техническое мышление.

\section{Abstract}

The article talks about innovative approaches to the training of technical teachers. The importance of humanistic orientation in technical education in general is also mentioned. Substantiations of the special role of meta-subject, transdisciplinarity in the course of training specialists for teaching technical sciences are given. The conditions and possibilities of training professionally oriented specialists in the field of education who are ready to modernize the modern educational process are considered.

Keywords: engineering activity, professional pedagogy, professional competencies, technical pedagogy, educational professional standards, technical thinking.

Инженерное образование с общенаучных позиций - это педагогическая теория, выступающая в качестве обоснования системы подготовки будущих инженеров и педагогов высших технических школ. На сегодняшний день профессиональная деятельность инженеров является многофункциональной; она наполняется интегрированным научно- 